\title{
VIABILIDADE DE SEMENTES DE PAPUÃ (Brachiaria plantaginea) E A COBERTURA DO SOLO COM PALHA
}

\author{
ALEXANDERGRASS (Brachiaria plantaginea) SEED VIABILITY AND \\ SOIL COVER WITH STRAW
}

\author{
Giovani Theisen $^{1}$ e Ribas Antonio Vidal $^{2}$
}

\section{RESUMO}

$O$ objetivo deste trabalho foi determinar o efeito de palha de aveia preta (Avena strigosa) sobre o solo, na dormência e quiescência de sementes de papuã (Brachiaria plantaginea). Os tratamentos testados foram cobertura do solo $(0 ; 2,6 ; 5,2 ; 7,8$ e 10,5t/ha), o tempo de permanência das sementes submetidas à ação da cobertura do solo (40, 70, 100, 200 e 300 dias) e o posicionamento das sementes $(2$ e $10 \mathrm{~cm})$. Elevados níveis de cobertura sobre o solo aumentaram o percentual de sementes de papuã viáveis. Sementes próximas da superfície do solo apresentaram menor dormência e quiescência do que aquelas posicionadas a $10 \mathrm{~cm}$ de profundidade. A dormência e a quiescência das sementes de papuã se reduziram com o decorrer do tempo.

Palavras-chave: conservação do solo, dormência, ecodormência, planta daninha, plantio direto, quiescência, resíduos vegetais.

\section{SUMMARY}

The objective of this work was to determine the effect of black oat (Avena strigosa) residues on the viability of alexandergrass (Brachiaria plantaginea) seeds. The factors studied were the level of residues on the soil (0, 2.6, 5.2, 7.8 and $10.5 \mathrm{t} / \mathrm{ha}$ ), the time of permanence of seeds in soil submitted to action of residues (40,70, 100, 200 and 300 days) and the seed placement (2 and $10 \mathrm{~cm}$ ). High levels of crop residues on the soil surface increased the seed viability. Seeds placed at $2.0 \mathrm{~cm}$ presented smaller dormancy and quiescence than those at $10 \mathrm{~cm}$ depth. Seed dormancy and quiescence were reduced with time.

Key words: dormancy, ecodormancy, no-till, quiescence, soil conservation, vegetable residues, weed.

\section{INTRODUÇÃO}

A dormência das sementes é um processo complexo, regulado por fatores genéticos, e sob forte efeito ambiental. A temperatura é um dos principais fatores que regula a dormência das sementes, influenciando principalmente a superação da dormência primária, mas também afetando a dormência secundária (EGLEY, 1986). A flutuação térmica diária, para muitas espécies, pode afetar a germinação dentro da estação de crescimento (COPELAND \& McDONALD, 1986; EGLEY, 1986) e geralmente acelera a germinação das sementes. Por exemplo, a temperatura ótima para germinação de Bidens pilosa ocorre com variações entre 20 e $35^{\circ} \mathrm{C}$, diminuindo à medida que diminui ou aumenta acima desses valores (REDDY \& SINGH, 1992).

Além da temperatura, a luminosidade e hidratação também interferem no estado fisiológico das sementes. A hidratação das sementes interfere na dormência devido a fatores físicos (KHAN \& KARSSEN, 1980) e químicos, como a ativação de enzimas (FOOTITT \& COHN, 1995) e o aumento no metabolismo das sementes (LI \& FOLEY, 1996).

Das plantas daninhas infestantes das culturas de verão, o papuã (Brachiaria plantaginea) (BRAPL) é a gramínea de maior incidência no Rio Grande do Sul, sendo encontrada também em vários locais do Brasil, prejudicando o rendimento e qualidade da produção. Na cultura da soja, sua infestação

\footnotetext{
${ }^{1}$ Engenheiro Agrônomo, Aluno de Mestrado em Fitotecnia, Faculdade de Agronomia, Universidade Federal do Rio Grande do Sul (UFRGS).

2 Engenheiro Agrônomo, PhD., Professor Adjunto, Departamento de Plantas de Lavoura, Faculdade de Agronomia, UFRGS, Caixa Postal 776, 90001-970, Porto Alegre, RS. Pesquisador do CNPq. E-mail: vidal@if1.if.ufrgs.br, Autor para correspondência.

Recebido para publicação em 22.06.98. Aprovado em 09.12.98
} 
é a causa de perdas de até $82 \%$ no rendimento de grãos (FLECK, 1996). Além disto, a invasora tem aumentado sua nocividade, pois adquiriu resistência a alguns dos herbicidas utilizados em seu controle (VIDAL, 1997).

A manutenção da cobertura sobre o solo altera a temperatura, a luminosidade e o teor de umidade do solo, podendo alterar a viabilidade de sementes de plantas daninhas (BALL, 1992; CLEMENTS et al., 1996). Esta pesquisa teve por objetivos avaliar como a cobertura vegetal sobre o solo, a profundidade das sementes e o tempo afetam o estado fisiológico das sementes de $\boldsymbol{B}$. plantaginea.

\section{MATERIAL E MÉTODOS}

O experimento foi conduzido a campo, na Estação Experimental Agronômica da Universidade Federal do Rio Grande do Sul (EEA/UFRGS), em Eldorado do Sul, RS e complementado com análises executadas nos laboratórios da Faculdade de Agronomia da UFRGS, no ano agrícola 1996/97. O solo onde foram realizados os experimentos é classificado como Podzólico vermelho-escuro distrófico (PAULEDULT).

O delineamento experimental foi o de blocos casualizados, sendo os tratamentos organizados em parcelas subsubdivididas, com cinco repetições. Nas parcelas principais, considerou-se o nível de cobertura do solo $(0 ; 2,6 ; 5,2 ; 7,8$ e 10,5 t/ha $)$, nas subparcelas, a profundidade das sementes (2 e $10 \mathrm{~cm})$, enquanto nas subsubparcelas considerou-se o tempo de avaliação (40, 70, 100, 200 e 300 dias após a colocação da palha sobre o solo (DAT)).

Cada parcela tinha $3 \mathrm{~m}^{2}(2 \times 1,5 \mathrm{~m})$, nos quais foram abertas perfurações com $11 \mathrm{~cm}$ de profundidade, para armazenar envelopes de tela plástica $(10 \times 12 \mathrm{~cm})$, contendo 1000 sementes de BRAPL cada, a 2 e $10 \mathrm{~cm}$ de profundidade. Esse procedimento foi executado no período de inverno, em área cultivada com aveia-preta em semeadura direta. Em novembro, a cultura foi dessecada, adicionando-se os níveis de palha sobre as parcelas. Nos períodos de avaliação, as amostras foram exumadas e se quantificou $\mathrm{o}$ estado de dormência e sobrevivência das sementes.

Após a limpeza e secagem, os envelopes foram armazenados em geladeira por cinco dias, sob temperatura de $7^{\circ} \mathrm{C}$. Após este período, retiraram-se aleatoriamente 150 sementes de cada envelope, acondicionando-as em placas-de-Petry sobre um papel-filtro, sendo levadas para câmaras com temperatura controlada, alternando a mesma entre 8 e $30^{\circ} \mathrm{C}$ (12 horas), mantidas secas por sete dias. Visou-se, através desse processo (conhecido por afterripening,
DUKE (1985)), minimizar a presença de sementes em estados intermediários entre dormência e quiescência.

Ao final do período de afterripening, estabilizou-se a temperatura das câmaras de crescimento para $22^{\circ} \mathrm{C}$ e adicionou-se água às sementes. A cada dois dias, determinou-se o número de sementes germinadas em cada placa, descartando-se as plântulas. Consideraram-se germinadas as sementes que apresentavam ao menos $0,5 \mathrm{~cm}$ de parte aérea e radicular (NORTHAM \& CALLIHAN, 1994).

A quiescência das sementes foi estimada pelo percentual de germinação imediata em ambiente favorável, determinada pela razão percentual entre número de sementes germinadas e o tamanho inicial da amostra no teste de germinação (150).

Após a análise de germinação, retiraram-se 25 das sementes remanescentes em cada placa-dePetry, cortando-as longitudinalmente e mergulhadoas em solução de tetrazólio a $1 \%$, por 6 horas a $22^{\circ} \mathrm{C}$. Foi considerada dormente a semente que apresentava coloração avermelhada em seu embrião, enquanto que as demais foram consideradas mortas. $\mathrm{O}$ percentual de sementes dormentes, indicado pelo teste de tetrazólio, foi obtido pela seguinte expressão (1):

$\mathrm{D} \%=\frac{(\mathrm{Ai}-\mathrm{Q}) \cdot \mathrm{TV}}{\mathrm{Tb}} \cdot \frac{100}{\mathrm{Ai}}$,

onde: Ai é o tamanho inicial da amostra (150 sementes); Q é o número de sementes quiescentes; Tv é o número de sementes viáveis no teste de tetrazólio; e Tb é o tamanho da amostra utilizada no teste de tetrazólio (25 sementes).

Os resultados foram submetidos à análise de variância e os graus de liberdade dos tratamentos testados foram desdobrados em regressão linear, quadrática e desvio destas (RIBOLDI, 1993).

\section{RESULTADOS E DISCUSSÃO}

A dormência das sementes de BRAPL foi afetada pela cobertura de palha no solo, pela sua profundidade e pelo tempo de permanência, não havendo interação entre estes fatores.

A dormência de sementes de BRAPL foi de 9\% quando o solo apresentava-se sem cobertura vegetal e aumentou de forma quadrática com incremento de palha na superfície do solo, atingindo valor máximo com 7,8t/ha de palha (figura 1).

Analisando-se o efeito do tempo na dormência de BRAPL, verifica-se que o percentual de sementes dormentes diminuiu de forma linear com sua permanência no solo. As sementes apresentaram, aos 300 DAT, cerca de $28 \%$ da dormência observada aos 40 DAT (figura 2). 


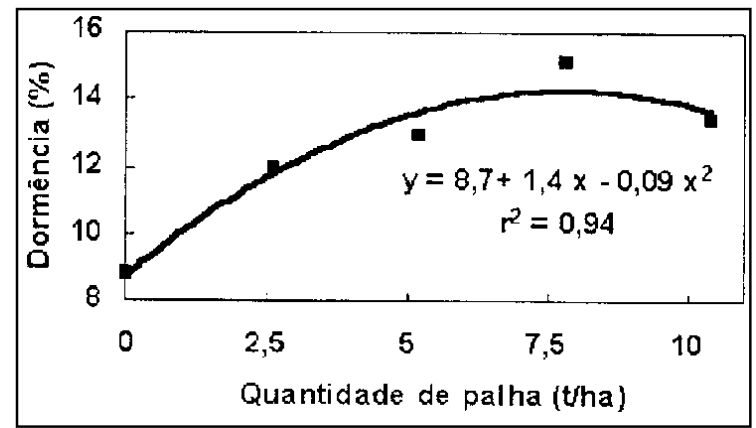

Figura 1. Efeito da quantidade de palha na superfície do solo na dormência de sementes de Brachiaria plantaginea, na média de duas profundidades e de cinco épocas de avaliação. EEA/UFRGS, Eldorado do Sul, RS, 1997.

As sementes posicionadas a $10 \mathrm{~cm}$ apresentaram maior dormência do que aquelas a dois centímetros, mas, em ambas profundidades, a dormência se reduziu de forma semelhante com o decorrer do tempo, sugerindo que o efeito do tempo atuou independentemente da posição das sementes no solo (figura 2).

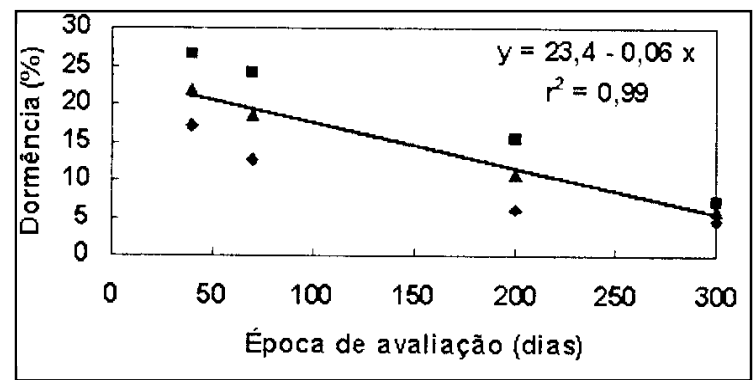

Figura 2. Dormência de sementes de Brachiaria plantaginea com o decorrer do tempo, na média de duas posições no solo: $2 \mathrm{~cm}(\bullet)$ e $10 \mathrm{~cm}(\boldsymbol{\square})$.EEA/UFRGS, Eldorado do Sul, RS, 1997.

A quiescência das sementes variou em função dos fatores principais e das interações entre palha $\mathrm{x}$ profundidade e palha $\mathrm{x}$ épocas. $\mathrm{Na}$ avaliação realizada aos 40 DAT, observou-se aumento quadrático da dormência, quando os níveis de palha aumentaram de 0 para 10,6t/ha (Figura 3). Nas demais épocas de avaliação, não houve ajuste de equações linear ou quadrática (figura 3). De maneira geral, maiores quantidades de palha na superfície do solo elevaram a quiescência, enquanto o aumento no tempo diminuiu a quiescência das sementes (figura 3).

A quiescência das sementes reflete sua capacidade de germinar assim que o ambiente for favorável. Com o decorrer do tempo, observou-se declínio desta capacidade, provavelmente devido às CONCLUSÕES

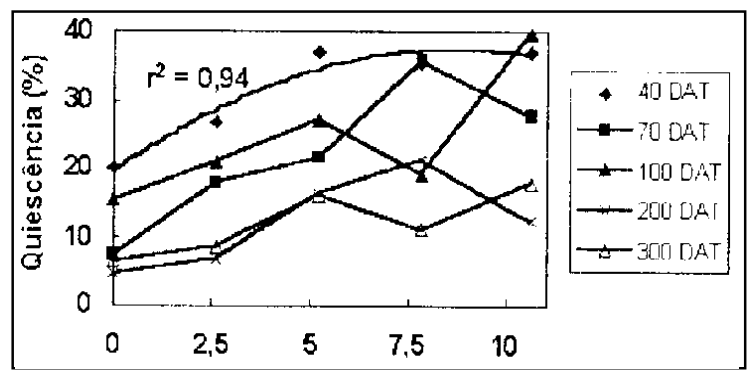

Figura 3. Efeito da quantidade de palha na quiescência de sementes de Brachiaria plantaginea em cinco épocas de avaliação, na média de duas posições no solo. EEA/UFRGS, Eldorado do Sul, RS, 1997.

alterações fisiológicas, predação e senescência das sementes.

Sementes em solo descoberto diminuíram sua quiescência mais rapidamente do que aquelas maiores quantidades de palha.

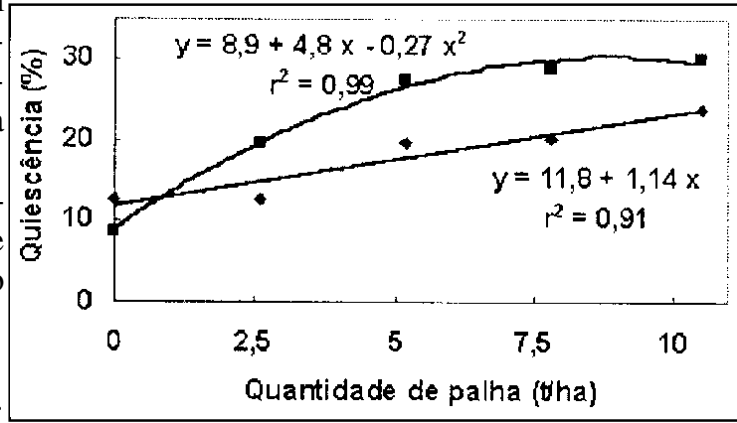
Observou-se, Figura 4. Efeito da quantidade de palha na quiescência de seaos $300^{\text {Figura }}$ mentes de Brachiaria plantaginea posicionadas aos DAT, cerca $2 \mathrm{~cm}(\bullet)$ e $10 \mathrm{~cm}(\square)$ no solo. EEA/UFRGS, Eldorado de $33 \%$ da do Sul, RS, 1997. quiescência ocorrida aos 40 DAT (figura 3).

Observou-se maior quiescência das sementes posicionadas a 10 do que aos $2 \mathrm{~cm}$, exceto para solo sem cobertura vegetal (figura 4). Maiores quantidades de palha recobrindo o solo elevaram a quiescência, tanto para sementes posicionadas a 2 quanto a $10 \mathrm{~cm}$. Porém, nas sementes próximas da superfície, o incremento de 0 para 10,5t/ha de palha aumentou a quiescência em $87 \%$, enquanto nas sementes localizadas a $10 \mathrm{~cm}$ a diferença entre os tratamentos foi superior a 240\% (figura 4).

Os tratamentos testados modificaram o ambiente afetando a quiescência e a dormência das sementes de BRAPL. A variação térmica é um dos fatores mais influentes no estado do banco de sementes de BRAPL no solo (CAROLLO et $\boldsymbol{a l}$., 1997), e especula-se que tenha sido um dos principais fatores responsáveis pelos resultados observados. 
Níveis crescentes de cobertura do solo com palha de aveia e a manutenção de sementes em camadas profundas no perfil do solo mantêm as sementes de Brachiaria plantaginea em estado de dormência.

Ocorre elevado percentual de sementes de B. plantaginea quiescentes quando o solo está coberto com palha e quando as sementes estão dispostas distantes da superfície do solo.

Com o decorrer do tempo, de 40 para 300 dias após a colocação da palha, ocorre redução na dormência e na quiescência das sementes de $\boldsymbol{B}$. plantaginea.

\section{AGRADECIMENTOS}

Agradecemos ao apoio de Cléo M. Carollo e Eduardo A. Manjabosco. Trabalho parcialmente financiado por CAPES, CNPq (520057/96-1) e FAPERGS (95.00901-2).

\section{REFERÊNCIAS BIBLIOGRÁFICAS}

BALL, D.A. Weed seedbank response to tillage, herbicides, and crop rotation sequence. Weed Science, Champaign, v. 40, n. 4, p. 654-659, 1992.

CAROLlO, C.M., THEISEN, G., VIDAL, R.A. et al. Germinação de leiteira (Euphorbia heterophylla) e papuã (Brachiaria plantaginea) submetidos a diferentes tratamentos de temperatura. In: SALÃO DE INICIAÇÃO CIENTÍFICA 9, 1997, Porto Alegre, RS. Livro de Resumos... Porto Alegre: UFRGS/PROPESQ, 1997. p. 99.

CLEMENTS, D.R., BENOIT, D.L., MURPHY, S.D. et al. Tillage effects on weed seed return and seedbank composition. Weed Science, Champaign, v. 44, n. 2, p. 314-322, 1996

COPELAND, L.O., McDONALD, M.B. Principles of seed science and technology. New York: McMillow, 1986. $321 \mathrm{p}$.
DUKE, S.O. Weed physiology: Reproduction and ecophysiology. Boca Raton: CRC, 1985. v.1, 161 p.

EGLEY, G.H. Stimulation of weed seed germination in soil. Reviews of Weed Science, Champaign, v. 2, p. 67-89, 1986.

FLECK, N.G. Interferência de papuã (Brachiaria plantaginea) com soja e ganho de produtividade obtido através do seu controle. Pesquisa Agropecuária Gaúcha, Porto Alegre, v. 2, n. 1 , p. $63-68,1996$.

FOOTITT, S., COHN, M.A. Seed dormancy in red rice (Oryza sativa). IX. Embryo fructose-2,6-bisphosphate during dormancy breaking and subsequent germination. Plant Physiology, Lancaster, v. 107, n. 4, p. 1365-1370, 1995.

KHAN, A.A., KARSSEN, C.M. Induction of secondary dormancy in Chenopodium bonus-henricus L. seeds by osmotic and high temperature treatments and its prevention by light and growth regulators. Plant Physiology, Lancaster, v. 66, n. 1 , p. $175-181,1980$

LI, B., FOLEY, M.E. Transcriptional and posttranscriptional regulation of dormancy-associated gene expression by afterripening in wild oat. Plant Physiology, Lancaster, v. 110, n. 4, p. 1267-1273, 1996.

NORTHAM, F.E., CALLIHAN, R.H. Interpreting germination results based on differing embryonic emergence criteria. Weed Science, Champaign, v. 42, n. 3, p. 474-481, 1994.

REDDY, K.N., SINGH, M. Germination and emergence of hairy beggarticks (Bidens pilosa). Weed Science, Champaign, v. 40, n. 2, p. 195-199, 1992.

RIBOLDI, J. Delineamentos experimentais de campo. Porto Alegre: Instituto de Matemática da UFRGS, 1993. 71 p. (Cadernos de Matemática e Estatística).

VIDAL, R.A. Herbicidas: mecanismos de ação e resistência de plantas. Porto Alegre: Palloti, 1997. $165 \mathrm{p}$

Ciência Rural, v. 29, n. 3, 1999. 